\title{
Glimmers of Care: Attending to the Affective Everyday in Ninth Grade Literacy Classrooms
}

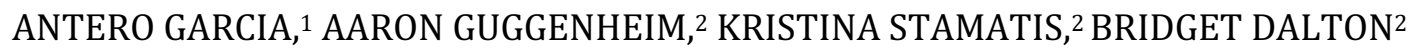

${ }_{1}^{1}$ Graduate School of Education, Stanford University, Stanford, CA, 94305

${ }^{2}$ School of Education, University of Colorado Boulder, Boulder, CO 80309, USA

This is the peer reviewed version of the following article:

Garcia, A., Guggenheim, A., Stamatis, K., Dalton, B. (2020). Glimmers of care: Attending to the affective everyday in ninth-grade literacy classrooms. Reading Research Quarterly.

which has been published in final form at https://doi.org/10.1002/rrq.296. This article may be used for non-commercial purposes in accordance with Wiley Terms and Conditions for Use of SelfArchived Versions. 


\title{
Glimmers of Care: Attending to the Affective Everyday in Ninth Grade Literacy Classrooms
}

\author{
ANTERO GARCIA, ${ }^{1}$ AARON GUGGENHEIM, ${ }^{2}$ KRISTINA STAMATIS, ${ }^{2}$ BRIDGET DALTON² \\ ${ }^{1}$ Graduate School of Education, Stanford University, Stanford, CA, 94305 \\ ${ }^{2}$ School of Education, University of Colorado Boulder, Boulder, CO 80309, USA
}

\begin{abstract}
In this qualitative study, the authors examined how care was enacted, understood, and valued by teachers and students in nine ninth-grade English language arts classrooms. Following two yearlong cohorts of teachers, the authors explored sociopolitical interpretations of care, specifically focusing on how care was an everyday, political phenomenon in the classrooms. Drawing on observations, teacher and student surveys and interviews, and students' multimodal compositions and artifacts, the authors analyzed glimmers of affect within and across classrooms. The authors framed their findings around two vignettes to illustrate how clusters of analytic glimmers revealed three dimensions of political, everyday care in the classrooms. First, care was shaped by the structures of space and pedagogy in classrooms, such as the requirements imposed on student composition. Second, the manipulation of the actual space of classrooms-the positioning of desks and bodies - shaped care. Finally, the materiality and modality of student production in classrooms highlighted both the platforms on which students demonstrated forms of care and the authoring decisions they made. The authors conclude with specific suggestions for using glimmers as a methodological approach in other affective studies and for designing classrooms that provide avenues for students to shape the enactments of care in classrooms.
\end{abstract}

The darkened school media center hosted parents, students, and teachers who came together to watch the film festival that Mr. Lincoln's (all names are pseudonyms) students had produced. The word torn flashed on the screen, followed by an X-ray of a young woman with scoliosis. There was silence from the audience, space where a gasp might be heard, as Sara's voice-over recounted the surgery meant to straighten her spine. As she described the pain surrounding her experience, her voice was calm, measured, almost clinical: "Right before my surgery, I had about a 70-degree curve in my spine. It took only about 10 months for my scoliosis to progress that much." The audience members shifted visibly, straightening, adjusting against the weight of her words. Sara's voice continued, describing the emotions that she encountered as a 13-year-old unable to do anything for herself for over two weeks after surgery. The video featured a full screen photo of Sara's post-surgery scar. It faded during the final scene as she narrated, "It makes you feel utterly helpless...like a failure, a disappointment.... The feeling of being a burden sticks." The film ended, and the room filled with quiet rustling of bodies and murmurs. One parent exhaled audibly and said, "That was really brave." Later, in an interview, Sara recounted her mother's concern that showing her scar might leave Sara vulnerable, but the nervousness that Sara felt about sharing "something so personal" was countered by the need to say, "You will be able to get through [difficult things], and [they] might turn out to be something that you will appreciate happening."

This study was born out of three years of observation in nine grade 9 classrooms where we collaborated with teachers to integrate feelings and practices of care into English language arts (ELA) as part of a project-based learning curriculum (Boardman, Garcia,\& Dalton, in press). Like Sara, we found ourselves noticing the stickiness of feelings (Ahmed, 2015) as they occur in everyday experiences with care.

Sara's story, and her audience's reactions, moved us to consider the ways that school spaces glimmer with complex feelings as bodies move and are moved through the words, actions, and materials that dwell within sites of literacy (Muñoz, 1996). Sara's decision to display her scar on screen revealed her everyday reality and allowed her to care for herself by pushing back against societal views 
GLIMMERS OF CARE: ATTENDING TO THE AFFECTIVE EVERYDAY

about how the body, especially young women's bodies, should be displayed in public. This decision both met the day-to-day requirements of her English class and offered a deeply felt personal and political message about body image and representation. Sara's vulnerability reverberated against and among the experiences of others, allowing for care to occur differently for each audience member. Whereas her mother expressed her care as worry, a more distant observer recognized and celebrated Sara's bravery. Sara, too, felt the weight of her video story. She made an explicitly political and personal decision to show her body's differences and acknowledged the vulnerability of revealing her scar on screen to a community audience. Sara did not know how care might manifest, but she was compelled to reach out to others in the audience who could learn from the feelings evoked through her story.

Acknowledging that Sara's story was both unique and representative of many students' experiences in our study, we explored how care was felt as an affective and political phenomenon (Ahmed, 2015). As a team of literacy researchers and former classroom teachers with commitments to equity, we turned to affect theory to make sense of the visceral moments that we experienced and observed across classrooms. We noted these visceral moments, like those that Sara and her audience encountered, because they were often felt before we could name them (Dutro, 2013). As teachers, we have experienced how standards and best practices, although helpful as pedagogical guideposts, can potentially block us from noticing how we and others are feeling, moving, and thinking across moments. Reflecting on these experiences in our research has led us to question what it means to examine care as a phenomenon in literacy spaces and to recognize that the ways we theorize and enact care matter for students' experiences in classrooms, for teachers' instructional practice, and for how researchers attend to the political within affect and literacy scholarship.

We drew on affect theory to investigate everyday experiences of care because we sought to attend to care as an ever-political act that is felt in the everyday ordinariness of life and school (Ahmed, 2015; Gutiérrez et al., 2017; Stewart, 2007; Vasudevan,2014). These everyday moments and movements can be as small as students deciding (or being told) where to sit in the classroom but accrete in ways that texture learning experiences. We conceptualize affect as produced in an ever-shifting assemblage of bodies, materials, and nonmaterial things both within and outside of classrooms (Ehret \& Hollett, 2014; Highmore, 2010). We understand care as affective, circulating between bodies and objects, sticking and moving in different ways for different people. In framing care as political, we also call attention to how bodies move and structure affect as they are governed and aligned by social, historical, and cultural practices that privilege some and deny others (Ahmed, 2000).

Throughout our analysis, we gathered glimmers - ephemeral, visceral sensations that both lingered for us as researchers and were acknowledged by our participants - to explore the daily forms of care that students like Sara felt and expressed (Muñoz, 1996). Glimmers, as an analytic tool, call for the historicizing of classrooms to orient us toward how bodies affect and are affected by others in moments that extend across varying temporal scales. Tracing glimmers through the actions, spaces, and materials that produced them, while also acknowledging them as discrete sensations, can illuminate how affective experiences are both entangled within institutions and exist outside of these structures (Highmore, 2010). Like fireflies that shine brighter as they are collected en masse, the grouping of glimmers can lead us to witnessing how affect moves within everyday moments of care that may otherwise be obscured within the normative structures of schooling.

Our interest in care grew out of a desire to understand how students and teachers in this study connected their lived experiences to the products that they created and to their interactions with one another. We were intrigued by the ways that teachers' intentions of care sometimes appeared to be felt quite differently by students. Our understandings of glimmers began to take shape as we took note of how expressions of care - a hand placed on a shoulder and the body shrinking away, reaching out to an absent classmate and the classmate's return-were experienced and layered across participants in classrooms. Through our study of two yearlong cohorts of nine grade 9 ELA classrooms, we attempted to grapple with teachers' and students' experiences of care. In particular, we used glimmers as an analytic frame to explore the question, How does affect shape care in the everyday experiences of 
students and teachers in classrooms?

\section{RELATED LITERATURE}

For a study looking across multiple classrooms, we built from understandings that feelings of care continually reshape and are shaped by teachers and students as they interact with the materials of schools. We linked feelings of care to affect theory, specifically grounding this work in literature on the political dimensions of affect (Ahmed, 2015) and on everyday moments of schooling (Gutiérrez et al., 2017). Further, we contextualized our analysis within a project-based learning framework and curriculum (Polman, Stamatis, Boardman, \& Garcia, 2018), exploring teaching and learning practices and student products across multiple school years and three schools, emphasizing how space and history frame the ways that bodies move, feel, and make.

Literacy scholars have responded to the affective turn in cultural studies and poststructural scholarship by exploring how affect structures literacies in "density and texture as they move through bodies, dreams, dramas, and social worldings of all kinds" (Stewart, 2007, p. 3). This affective approach to literacies pushes on established perspectives that emphasize "language and other modes of meaning [as] dynamic representational resources, constantly remade by their users as they work to achieve their various cultural purposes" (New London Group, 1996,p. 64). In our study, we took affect to be emergent (Leander \& Boldt, 2013), visceral (Dutro, 2013), and political (Ahmed, 2015) as it is formed and reformed in relation across and through assemblages of objects, bodies, and spaces (Lenters, 2016, 2019). To seek these affective turns within the everyday care of students and teachers, we used glimmers as a metaphor, imagining these moments of felt and voiced intensity as clustered together so they were able to be noticed by others. We do not argue that affect is inherently liberatory (Massumi, 2015). Rather, affect holds potential to both liberate and control, at times moving young people toward visceral ways of knowing and, at other times, moving them into normative modes of thinking, feeling, and becoming within classrooms (Dutro, 2019).

\section{Care in Educational Research}

Particular to our study's context, we focused on care as part of the affective experiences constantly flowing through classrooms. Care in educational research has often been framed as something that is done for students (Noddings, 1992) or as an interaction inside classrooms (Valenzuela, 1999) mediated by actors and tools within sociocultural contexts (Lewis \& Tierney, 2011; Vadeboncoeur \& Collie, 2013). These approaches can position teachers as both role models and partners in producing caring classrooms (Noddings, 2006) and can be text-centric when drawing on emotion as a form of mediated action (Lewis $\&$ Tierney, 2011). Although we understand care to be socially constructed and mediated by contexts, materials, and bodies, we also illustrate how care affects and can be affected by the politics of schooling and its intersection with the ways that some identities have been historically marginalized.

Approaches to care have been operationalized in social and emotional learning (SEL) frameworks that seek to address the social and emotional needs of students in schools (Osher et al., 2016). SEL is centered around an interlinked set of competencies that seek to prepare students to both participate in school and enter the workforce as "socially and emotionally competent" (Elias et al., 1997, p. 6). Many variations of K-12 SEL programming are sold to school districts as curricular and professional development packages (Williamson, Modecki, \& Guerra, 2015). However, care can be positioned as a byproduct of, rather than central to, SEL competencies and programs. Further, these SEL programs are often presented as culturally and politically neutral, when in fact they are experienced differently by different individuals (Hoffman, 2009).

These approaches to care risk reifying how oppression can structure and constrain opportunities, acting as "an excuse to ignore the social conditions that give rise to the need for those interventions" (Kirshner, 2015, pp. 28-29). Given how decontextualized SEL frameworks may attempt to center care while simultaneously cloaking inequities, it was important to position our framing of care as political in conversation with how other approaches to care have taken hold in schools. We therefore examined the ways that caring practices intersected with the felt and embodied experiences of teachers and students 
GLIMMERS OF CARE: ATTENDING TO THE AFFECTIVE EVERYDAY

as they drew on our approach to content-embedded SEL within project-based learning that focuses on caring, advocacy, perspective taking, and empathy.

\section{Care as an Everyday and Political Phenomenon}

In this article, care is a political and affective phenomenon (Ahmed, 2015) that occurs within everyday interactions (Gutiérrez et al., 2017; Vasudevan, 2014) as people and material and nonmaterial things interact and produce affective intensities (Ehret \& Hollett, 2014). Emergent feelings of care are produced in "the sticky relation between signs and bodies...working through signs and on bodies to materialise the surfaces and boundaries that are lived as worlds" (Ahmed, 2015, p. 191). These sticky moments sometimes seem short-lived but can accumulate and glimmer long after they have occurred. Conceptualizing the political and affective dimensions of care lends insight into how different forms of caring by researchers, teachers, and students have the potential to challenge how bodies move and are moved across and between literacy spaces (Ahmed, 2015; Zembylas, 2016).

Building from Ahmed (2015), emotions stick to some bodies and not others in ways that shape and reshape our social and political landscapes. This means that we need to consider not only how emotions stick and then glimmer together but also how these affective glimmers carry historical freight as "histories are bound up with emotions precisely insofar as it is a question of what sticks, of what connections are lived as the most intense and intimate" (p. 54). In this article, we attend to these considerations by explicitly naming care as political, examining how emotions are both lived out in the present and historicized, orienting how people move and are moved in social space (e.g., Gutiérrez et al., 2017).

Approaching care as affective and political means that caring can and will look, sound, and feel different based on the identities of the people between whom caring is happening. Educational institutions have the potential either to acknowledge and disrupt histories that marginalize or to bury these histories and their connected emotions as they circulate in the spaces that youth and educators inhabit. When care is framed as political, we are pushed to account for the intertwined affective experiences of both the caregiver and the cared for.

As an everyday practice, care does not have to be extraordinary to be recognized as valuable; it glimmers because of, not in spite of, its everydayness. Stewart (2007) termed these resonances of the everyday as "ordinary affects": "the varied surging capacities to affect and to be affected that give everyday life the quality of a continual motion of relations, scenes, contingencies, and emergences" (pp. $1-2)$. Anchoring investigations of the political and affective dimensions of everyday care supports attention "to seeing novelty, creativity, and ingenuity" (Gutiérrez et al., 2017, p. 54) in how people move and are moved in ways that can "question categories that may go unchallenged, and identify solutions that can address the institutional constraints in which people are placed" (Gutiérrez et al., 2017, p. 45). Caring is grounded in the task of acknowledging and acting on the emotions that one feels and recognizes in others; it is an ongoing and proactive process, shaped and framed by the affective experiences of youth and teachers in classrooms. In this article, we explore how these affective experiences glimmered together across materiality, modality, and histories, leading to specific and different interpretations of care.

\section{METHODS}

\section{Participants and Setting}

This study took place with two cohorts over two academic years in nine grade 9 ELA classrooms. The U.S. Mountain West schools that housed these classes were in rural/ suburban school districts. Four teachers were from Cunningham District, and five teachers were from Pike District. They self-identified as white and female (seven) or male (two), and all had at least seven years of teaching experience.

In the 2016-2017 school year, the rural Cunningham District's student population was $84 \%$ white, 14\% Latinx, and less than 1\% black, Asian, Pacific Islander, or Indigenous, and $15 \%$ of the students received free or reduced-price lunch. The Pike District, a mix of mountain, rural, and city regions, served 
GLIMMERS OF CARE: ATTENDING TO THE AFFECTIVE EVERYDAY

a student population that was $73 \%$ white, $19 \%$ Latinx, 3\% Asian, 3\% identified as two or more races, $1 \%$ black, and less than $1 \%$ identified as Native American or Pacific Islander, and $31 \%$ of the students received free or reduced-price lunch. We focused our analysis on 217 permissioned students, attending specifically to one or two focal students in each classroom. We selected the focal students to illustrate a range of student experiences and histories with schooling.

As districts serving predominantly white youth, the histories of these communities shaped how we understood the everyday and political instantiations of care in classrooms. The communities were built on the unceded territories of the Arapaho, Cheyenne, and Ute Nations. Buried histories, although unacknowledged visibly in these learning environments, have become part of the affective backdrop that frames these institutions. The present realities of these communities further shaped the political care already set within these schools. The specter of neighborhood oil wells and fracking stations, for example, contrasts with vast stretches of solar panel fields, wind turbines, ranches, and agricultural fields. These physical markers of space were complemented by rhetoric from the 2016 U.S. presidential campaign expressed on local storefront windows, bumper stickers, and yard signs. The state includes both liberal and conservative communities. Although surrounded by and part of these political rhetorics, teachers in each district were warned not to incite politics in classroom discussions, even as they were asked to teach for equity and justice.

The schools in this study were built between 1965 and 1975 and featured the prefabrication materials - small windows and fluorescent lights - of that era. Although each school was remodeled in the 1990s, renovations focused on common spaces rather than individual classrooms, and most of the learning environments that we observed remained constrained by their original designs. Classes tended to be large, averaging 27 students, and teachers struggled to find ways to seat students in desks so they could both collaborate on projects and see the front of the room where teachers often led instruction alongside a projector screen showing an agenda and online educational materials.

\section{Curriculum and Learning Experience}

Affect is situated, and context matters. We collaborated with teachers to codesign and formatively develop Compose Our World, a project-based ELA curriculum (Boardman et al., in press) that is based on principles of project-based learning (Polman, 2012), universal design for learning (Meyer, Rose, \& Gordon, 2014), and SEL (Collaborative for Academic, Social, and Emotional Learning, n.d.). The driving goal is to transform what it means to engage with ninthgrade ELA in ways that support students to collaboratively pursue interest-driven projects, work with authentic tools and practices, and iteratively compose products and performances for authentic audiences, guided by peer and teacher feedback and mentors (Polman, 2012).

Our curriculum was built on the notion that students deserve to have authentic experiences that lead them to feel safe and confident in questioning, influencing, and composing their world(s). Compose Our World consists of four projects that can be taught across the year (see Figure 1). We focused our analysis on two projects - Unearthing Humanity and What Happened Here? - because the first was taught by all nine teachers and the second by eight of the teachers. (Teachers can choose to augment or replace one or more projects in the Compose Our World curriculum to ensure that they meet local goals and conditions.) Although we know that this context is important to our study, we also believe that teachers' and students' experiences will resonate across other ELA classrooms.

Each project culminates in a multimodal product or performance. For the What Happened Here? project, students compose a digital story combining images, audio, and written text for an audience of parents, community members, and classmates. For the Unearthing Humanity project, teams create a museum exhibit of individual artifacts and write an argumentative essay for an audience of parents, community members, and classmates. The importance of multimodality, tools, and materials emerged as central to affect and care and, thus, became a focus in our analysis. As Ms. Miller explained, the What Happened Here? video stories helped students see their commonalities and build trust because "the [narratives] really worked well because it was very vulnerable...[students] 
GLIMMERS OF CARE: ATTENDING TO THE AFFECTIVE EVERYDAY

had to put themselves out there."

Enabling a caring and supportive community was the bedrock on which we designed the Compose Our World curriculum, with a particular focus on care, advocacy, perspective taking, and empathy embedded in each lesson through content, pedagogical practices, and reflective tools. Care was also designed into our collaboration with teachers, understanding that care is part of an ecosystem in which teachers are recognized as whole persons whose role as educator is inextricably interwoven with their whole being. Thus, in the Compose Our World summer professional development workshops, the ongoing codesign sessions, and informal conversations online and offline, attention was paid to values and practices of care. For example, individual and group reflections prompted teachers' exploration of emotions and experiences about life inside and outside of the Compose Our World context, and conversations in our online community revealed a range of perspective taking and showing of support for one another through the ups and downs of innovating and implementing a new curriculum.

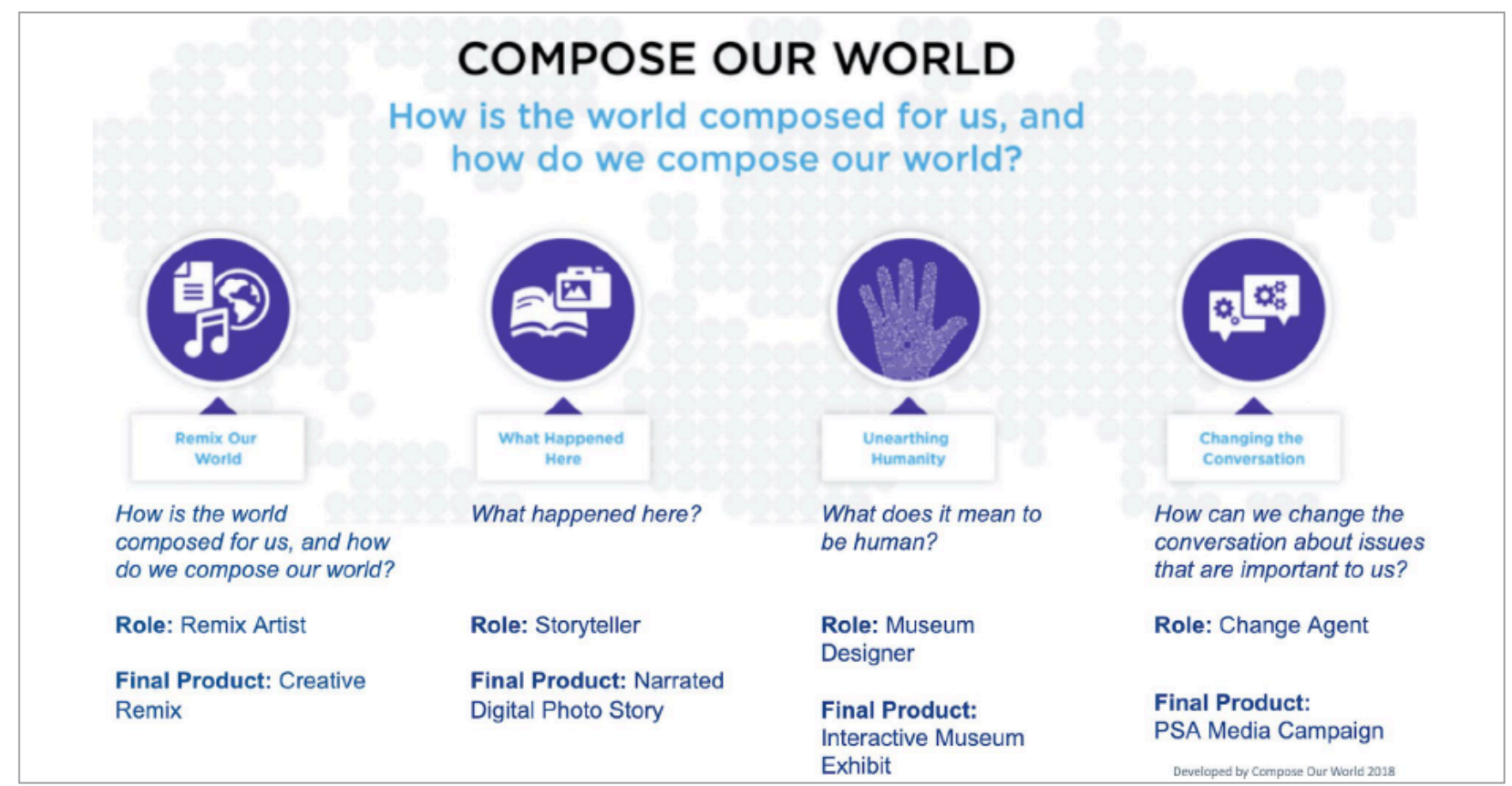

Figure 1. Compose Our World Project Overview

\section{Data Collection}

We collected multiple data sources: 10 classroom observations per teacher, project and end-of-year teacher interviews and surveys, instructional materials, and student work products, surveys, and focal student interviews for each project. The research team met weekly and, over time, constructed detailed teacher portrait memos of 5,000-7,000 words each to represent our understanding of the teachers' perspectives and practices, connected to students' experiences and perspectives. For example, we described teachers' project adaptations; use of care, advocacy, perspective taking, and empathy; and ways of talking about and positioning students, alongside a summary of students' perspectives on their experiences and feelings. These portraits allowed us to look across the nine classrooms and begin to identify the glimmers of care that were the basis of our analysis. The portraits led us back to the original data sources (e.g., interviews, field notes, student products) to develop more detailed and nuanced understandings of these glimmers, focusing on how teachers and students enacted and felt care within and beyond classroom literacy practices and spaces, as care fluidly traversed students' school, home, and community lives.

Our observation schedule for nine classes did not allow for a detailed following of day-to-day interactions. Instead, we layered data, observing how categories and themes emerged across different experiences. We noted everyday moments that felt significant to us and the ways that these moments 
GLIMMERS OF CARE: ATTENDING TO THE AFFECTIVE EVERYDAY

built over time to illuminate how affect circulated and stuck to bodies in these classrooms. Joining classrooms each week, we paid attention to our own feelings as a student's voice swelled with a sad memory or a body visibly shied away from a teacher's touch. We were moved as students shared themselves, and we were unsettled by microaggressions that we observed toward the few young people of color in these primarily white, rural classrooms.

\section{Analytic Glimmers}

We cannot claim to know what others felt. We acknowledge that data analysis is often a process through which "the Quality of experience is lost" (Ehret \& Leander,2019, p. 13). Therefore, we moved through our analysis by seeking glimmers of care noticed in classrooms and school spaces (Fosha, Siegel, \& Solomon, 2009). Much as Stewart (2014) used road registers to explore how emergent assemblages have "precise and shifting histories, generative forms, divergent social functions, and qualities that link it to countless other elements and partial assemblages" (p. 551), we looked to glimmers to shine light on the ways that affect built and shifted across bodies and spaces. We constructed meaning in classrooms from across the glimmers of care in our data; we did not attempt to analyze singular words or gestures divorced from the broader activities in which they were wrapped. Instead, these glimmers guided us toward interpreting care in the complex entanglements (Highmore, 2010) of affect that occurred within these classrooms. Care, as structured by affect within these literacy classrooms, supported our understandings of how youth's multiple literacies were being expressed, felt, and designed.

We understand glimmers not as positive or negative but as part of the everyday experiences of students and teachers. Although glimmers of affect may be easily overlooked, these experiences are illuminated when taken as a whole. Sara's story at the beginning of this article is an example of this glimmering within our observations. We only glimpsed her process, which appeared quiet and often individual, separate from her peers. However, we noted the intensity with which she worked and then observed the moment when her digital story was unveiled, when she felt the quiet that descended on her audience as her story played. It would be easy to take these moments as no more than a successful project with an authentic element that offered Sara agency within the classroom; however, by attending to the glimmers of emotion mentioned briefly in field notes, the constraints that Sara expressed feeling with her composition, and the care that she noted in her family's reaction to her project, we see these glimmers of emotions amalgamate into an affective experience that went much deeper. Rather than explicating and coding across multiple analytic themes, we collected these wisps of interrelated affect to reveal care aglow in different permutations for individuals in this study.

Having amassed substantial data across classrooms, we imagined affective glimmers as ephemera, "all of those things that remain after a performance, a kind of evidence of what has transpired but certainly not the thing itself" (Muñoz, 1996, p. 10). Instead of presupposing the ongoing feelings of students, of teachers, and amid the convergence of bodies and materials within and around classrooms, we sought out glimmers that illuminated care present in the everyday and which might be overlooked in singular fragments of data. Following Spinoza's (2000) reading of affect as the ability to affect and be affected, we recognized individual experience as deeply entangled with the other experiences and histories within each classroom. Each individual carried affective experiences into these classrooms and schools, and these experiences were noted through glimmers and taken together to point toward the affective intensities being experienced within these spaces. However, as our analysis highlights, these glimmers of care were felt differently by different individuals.

\section{Glimmering Within School Spaces}

Buildings are designed so certain kinds of power and agency are privileged over others (Hinchliffe, 2000). This power determines the shapes of walls and windows that direct and constrain how bodies, light, and air circulate. Schools, then, are designed to "preconfigure, limit, and engender particular affects to accomplish very particular goals" (Kraftl \& Adey, 2008, p. 213), even as critical educators and learners work to redesign and disrupt them. In describing the dialectic between affect 
GLIMMERS OF CARE: ATTENDING TO THE AFFECTIVE EVERYDAY

and architecture, Massey (as cited in Kraftl \& Adey, 2008) explained that "architecture is essentially a way of predetermining what we are 'thrown together' with" (p. 226). Bodies, and therefore the spaces and materials with which they interact, carry some moments longer than others (Kuby, Gutshall Rucker, \& Kirchhofer, 2015; Massumi, 2002).

For historically marginalized youth, this can mean that schooled spaces feel violent, even when violence is invisible to those who have not experienced it. These moments, embedded in personal and societal histories, shift the ways that young people read the world (Freire, 2000). Attending to these quakes of affect, which subtly shake students as they navigate their schooling, can help pull into focus the kinds of everyday, political care that glimmer across our data. In our analysis, we looked at the glimmers produced across students' experiences in designing multimodal literacy products and took into account the design of school spaces, which shape how care was felt in these classrooms. Our attention to the affective dimensions of care across participants allowed us to analyze care in classrooms in ways that are distinct from previous educational research that has framed care as produced because of programmatic interventions.

\section{Glimmers Within Multimodal Composition}

Across class periods, students produced in multiple modes - image, sound, movement, touch, and text - which were socioculturally and historically constructed and situated in particular contexts with associated practices and tools (Kress, 2003; New London Group, 1996). These products, and the processes of composing them, were felt in embodied ways throughout the classrooms (Leander \& Boldt, 2013). When looking at the glimmers of affect that arose during the production of these products, we found design to be a useful construct in thinking about how composers work with modes and tools to realize their creative visions (Dalton et al., 2015). Particularly as we considered multimodal design in relation to affect theory, we looked to multimodal projects as possible sites for surfacing how care is designed, felt, and enacted within assemblages of people, material, and social practices in and beyond classrooms (Lenters, 2016).

We foreground these findings by noting that all acts of composition are political because specific modalities, histories, experiences, and bodies are often centered in schools and engender certain types of affective production. At the same time, we acknowledge that multimodal composition and learning are situated within the cultural and historical practices of designers (e.g., Vasudevan, Schultz, \& Bateman, 2010). This positioning means that composing is always conducted within the political and the everyday theoretical framing that guided this study. It is therefore important to investigate not only the ways that teachers, researchers, and students designed and curated the spaces for learning and multimodal composing but also how these individuals and collectives brought their histories with them and ultimately shifted the designed spaces (Barad,2010).

\section{Limitations of Glimmers}

As researchers, we are only privy to glimmers of students' and teachers' experiences and feelings, to the ways that power manifests across histories and the ways that it may impact individuals within the spaces that we observe. Therefore, our investigation of the everyday, political dimensions of care could be only partial, grounded within context and limited by where and how we as researchers moved as we were analyzing data. Knowing the existence of feelings of care, ongoing and often in conflict with the expectations of school policies and structures, in our analysis of glimmers - across literacy spaces, histories, and modalities - we tried to acknowledge the unaccountable. This approach is a recognition of the limitations of this particular study and of sociocultural research more generally. From a sociocultural perspective, we designed this study to measure and interpret across the classrooms. Importantly, we discussed, reflected on, and categorized the inimitable feelings entangled within each classroom to consider how care was seen, elided, and acknowledged.

\section{FINDINGS}


GLIMMERS OF CARE: ATTENDING TO THE AFFECTIVE EVERYDAY

In lieu of overanalyzing outbursts of joy and sadness that were not regularly visible in our observations of the English classes in this study, we framed our findings around two vignettes, "Torn: Care Felt Through and With Others" and "Teachers Offering Care," which highlight the intersecting moments of everyday, political care that we observed in glimmers across nine classrooms. We layered our analysis around a series of moments that illustrated how histories, curricular expectations, modalities, and materialities glimmered together affectively to shape everyday experiences of care. We did not see these individual moments as fixed categories of analysis but rather as layers that intensified and brightened as they corresponded with each other. Delineating these moments in our analysis offered possibilities for sense-making around the ordinary affects present in the classrooms and how they shaped experiences of care. These experiences were not limited by the physical boundaries of the classroom or by individual bodies, but rather were a series of collective interactions across the many spaces where students and teachers felt, thought, and moved (Gutiérrez, 2008).

\section{Torn: Care Felt Through and With Others}

Sara, whose digital story about the spinal surgery to correct her scoliosis is featured at the beginning of this article, glimmered for us throughout our analysis of the data. She was a student at Redwood High School and composed her What Happened Here? story in Mr. Lincoln's class. He paired the digital story project with reading and literary analysis of the department-required novel To Kill a Mockingbird by Harper Lee.

In interviews and written reflections, Sara described her hesitancy to interact with others in her classroom, her painful history with her body, her frustration with the constraints of the assignment, and how she had constructed her story as a way to strengthen her relationship with her parents. In reflection about her decision to pursue this particular story, she wrote that she felt concern because "people might feel some pity... which is not the response that I want but I'm pretty sure at least one person will be sorry that this happened to me." She also realized how powerful it could be for her to share this story because it not only disrupted people's expectations for healthy bodies but also provided a way for her to express her feelings about her relationship with her parents:

[The video was] a way for me to connect to my parents about this, because one of the problems that I had after my surgery was that they tried to be there, but I didn't really feel like they were taking care of me. They got angry at me and I got angry at them, and at that point I had all this stuff going on inside my brain and I was just, like, yelling at them, and I'd never yelled at my parents before...it was really hard for me and I felt like a disappointment and a burden to them. My dad cried.

Although Sara described seeing her father's tears as an event outside of the everyday, she recognized that she carried the physical and emotional weight of this experience with her daily.

Sara also described the ways that the materials she used to make her digital story $-\mathrm{X}$-rays and photographs - brought an understanding of how her family viewed her body and its differences as she grew up through and beyond her surgery. She recalled sitting with her mom, opening boxes from a recent move to find the records and images from her hospital stay. Together, they dug through the images captured by her mom's smartphone, seeking moments of Sara in the hospital awaiting surgery, the first time she sat up without a curve in her spine, and the scar that was left on her back. Sara described choosing these images purposefully, first in an act of care for herself and later as a means of caring for her family and for the audience that might learn from her story. She told us that as they searched for pictures, her mother asked her over and over again, "Are you OK with people seeing your back?" and that she finally responded, "Yeah, I don't care. God, Mom, leave me alone."

Sara continued to explain,

In my family, like, everyone has body issues. That sounds weird, but everyone has trouble in my family with that. My mom's kind of, like, "Are you sure [you want to show your scar]?"... because that's been a problem for me in the past. 
GLIMMERS OF CARE: ATTENDING TO THE AFFECTIVE EVERYDAY

Sara and her mother navigated this tense space through the materials and modes available to them given their own intertwined personal histories and their perception of the place where the film would be shown. Sara ultimately took control; it was her story to tell, and she felt strongly about how to tell it and why to tell it to an audience where there might be someone also facing challenges.

As researchers, we felt our ways through multiple glimmers that flickered together into this narrative. The film that Sara produced functioned as one glimpse at expressed care in Mr.Lincoln's classroom, as did the uncommon tears of Sara's father, the memories of familial sifting through boxes of pictures, and the frustrations that arose for Sara from the constraints of aligning the product to the lessons of a classassigned novel. Each of these moments moved us, glimmering elusively until they were examined collectively. We interpreted these glimmers as layered experiences that can help illuminate the myriad lines of care found in the everyday and felt across and within bodies.

\section{Teachers Offering Care}

Each of the schools had established principles to guide the care in classrooms. The principles were often posted on the school website and on posters around the schools and in classrooms. Across schools, these principles juxtaposed "high standards for our learning community" with creating "a safe, positive, healthy learning environment" and caring for the "uniqueness of the individual." Teachers used these principles to frame their classrooms as spaces where students should hold themselves to high standards and feel valued as individuals. Across classrooms, we observed the ways that these two sets of expectations intersected and interrupted each other as teachers enacted care in their classrooms. We noted in field notes ways that school culture and care intersected and the ways that attempts at caring for individuals were often stifled because of the expectations of rigorous academic work. In the following vignette, drawn from Ms. Bryne's class during their Unearthing Humanity project, we see how feelings around care glimmer in anticipated and unanticipated ways as students built a museum of humanity to answer the question, "What does it mean to be human?"

Ms. Bryne decided to teach the Compose Our World curriculum later than her colleagues at Pine Ridge High School and expressed that she often felt like she was struggling to "find her footing." She described herself as "old school," a "content-driven" teacher who had

never been a fan of group work...as a student, I hated it desperately. I always ended up being the one doing the work, and I didn't like it. I felt like it was a way for lazy students to get away with stuff.

Despite her own negative feelings, she made it a goal to build relationships with her students, with the hope that it would help support all students in their group work. A primary means of building relationships was her daily routine of checking in with each student while they wrote reflections about the previous class in their digital journals.

Ms. Bryne's classroom was set up in long rows of desks with a large space in the center of the room. Ms. Bryne rarely turned on the lights in her classroom, relying instead on the wall of windows to naturally light the space. During her check-ins, she navigated between student desks, stepping over backpacks and kneeling down to offer students eye contact as she checked in on how they were feeling and on their progress on class projects. These everyday moments were one way that she designed for care, moving about the class to gather information that she would later incorporate into her teaching for that day. This time with students was important to Ms. Bryne, and although it was intended to take only 10 minutes, we observed that it often stretched much longer as Ms. Bryne made her way around the classroom. Although it often appeared that students responded positively to this personalized attention, one incident revealed how the affect surrounding care was felt differently by Ms. Bryne than by one her students, Abigail.

The session began with Ms. Bryne posting a question on the board asking students to reflect on a character from To Kill a Mockingbird and create a map explaining how they define humanity based on that character. Students sat in the darkened classroom, laptops open, talking quietly about the prompt, as Ms. Bryne walked between the desks and talked to individuals. Abigail, who was sitting next to the 
GLIMMERS OF CARE: ATTENDING TO THE AFFECTIVE EVERYDAY

researcher, leaned over to her partner and began recounting her weekend. Ms. Bryne approached and touched Abigail on the back: "How are you doing today, Abby?" she asked. "Fine," Abigail replied, shrinking her body away and returning to her conversation. "Make sure you're getting work done, too, OK?" Ms. Bryne said as she moved toward another student.

As the class moved on, Ms. Bryne prompted students to take out their character maps and work with a partner to write an essay that connected that character to the museum exhibit that they were building: "Your goal is to help us understand how you are defining what it means to be human and how that definition both connects to your exhibit and to the novel." She then continued to circulate a second time throughout the classroom, stopping once again next to Abigail to settle a hand on her shoulder and redirect her conversation toward the essay. Abigail and her partner compliantly began to discuss character development but were soon on Snapchat, looking at another student's profile and discussing his merits instead. During her third check-in, Ms. Bryne again knelt next to Abigail, placing her hand on her back and attempting to engage her in a conversation about her weekend before trying to redirect her toward the essay. Abigail shrunk down into her seat and away from Ms. Bryne. It was a small move, but it was felt by the researcher and noted as discomfort. As Ms. Bryne walked away, Abigail turned to the researcher and asked quietly, "Why does she keep touching me?" After class, Ms. Bryne told us that she had spent a lot of time during class trying to connect with Abigail because Abigail had lost both of her parents:

Abigail lives with her grandparents and her brother. Her mother died when she was really young, and her father was [dealing with addiction when he passed away.]... Can you imagine? I can't imagine what that girl goes through. She does really well for everything she's dealing with.

This moment glimmered for us because we recognized that whereas Ms. Bryne had intended to offer Abigail a physical sense of support and care within the classroom, Abigail had felt targeted and uncomfortable. The care that Ms. Bryne had intended to impart was received very differently by Abigail. This encounter illuminates how designing for care can be different from how it is experienced within and across classrooms, given the shifting flows of affective production and the histories within which those ordinary affects are constructed.

\section{From Glimmers of Care to Constellations of Care}

As moments of care are experienced across bodies, as with Sara and Abigail, they can be understood by the ways in which they occurred across a cluster of histories, spatial manipulations, and modalities. Here, we trace how the glimmers noted in our study coalesce into constellations of care by analyzing additional data on histories, modalities, and materialities and providing additional analysis of the previous vignettes.

\section{Histories of Spaces and Instruction}

Mr. Lincoln's classroom, where Sara and her peers composed their digital stories, was tightly packed with rows of desks. As they began class, students would file in from the crowded hallways, backpacks on shoulders, music playing from the speakers that Mr. Lincoln had put at the front of his classroom. As a means of connecting with his students, he invited students to email their music requests before the beginning of class, and he used their suggestions to create an environment that he hoped would feel welcoming and caring. Related, Mr. Lincoln's classroom was full of large posters of literary figures and student artwork.

Across our study, teachers made similar moves within their classrooms, working to incorporate student ideas to make their rooms welcoming. However, we noted in field notes that these rooms were also permeable and entangled with students' out-of-school lives. Space and movement in these classrooms were designed to support literacy practices. Although these spaces were authored by both students and teachers, the teachers often took the lead in visible ways. Mr. Lincoln and the other teachers in our study were in charge of constructing not only the visual and aural environments that 
GLIMMERS OF CARE: ATTENDING TO THE AFFECTIVE EVERYDAY

constrained their literacy spaces but also the assignments in which students took part. These assignments offered glimmers pointing to how teachers typically held agency within classrooms, controlling what students created and therefore how affect was acknowledged.

Mr. Lincoln had reported that his own histories of instructional practice had not been project based-he taught novels and focused on literary analysis of, for example, how characters develop over the course of a text-and he was not sure if students in his previous classes had opportunities to voice and address the things that they cared about. He recounted that he typically taught novels, such as To Kill a Mockingbird, supplemented by vocabulary instruction and online grammar units. Although the What Happened Here? digital story project was designed to disrupt the ways that students brought their own experiences into classrooms, Mr. Lincoln's history as a ninth-grade teacher and the school's emphasis on "academic rigor" led him to forefront the requirements of the assignment rather than students' emotional experiences as they constructed their digital stories. Although he expressed care through holding students to what he considered "high standards," the histories of these instructional practices, and the demands of his department, led to constraints on what and how students produced during these projects.

These instructional histories glimmered strongly as constraints on care, particularly when examined in the context of Sara's experience with her digital story. Although she had chosen what story to tell, she expressed feeling frustrated by the requirement to add music. Sara remarked during an interview that she had not wanted to use music in her digital story but that the rubric stated, "If you don't use music, you're going to lose points." She explained that if she could change anything, "I would take the music out, honestly, because I only added it for a grade." Considering the very deliberate decision to show a photo of her scar for 15 seconds - an eternity of audience viewing - the intrusion of classroom requirements highlighted disconnects between student care in designing and adult instructional discretion, even if these decisions were initially rooted in care or compliance. When asked in an interview what she would change about her experience, Sara even expressed that she was still considering removing the music so the video held only her voice. Although Sara was able to share her own story, one that was deeply personal, the emotion and care that she was able to evoke within that telling were still constrained by the requirements that Mr. Lincoln had added to the assignment. These constraints dictated which affective experiences were allowed to be evoked and acknowledged in this classroom.

In designing her film, Sara had to weave together her own self-care, making choices that simultaneously honored her experiences and intersected with assumptions about what elements must be included for her product to be considered a "good" video. Similarly, we noted teachers navigating the constraints of their district policies while building what they hoped were caring classroom experiences for their students and attending to their own sense of well-being and self-care. Mr. Lincoln was "proud of what we [the Compose Our World community have] done, and I feel like we've done some cool things. I feel more sane than usual and healthier." Recognizing that changes do not come solely through grading and measuring academic growth, he noted that changes through this project were "more like the personal engagement and the empathy and everything. I think that it has, like, a human payout that is pretty awesome, so that's one thing. Just on a daily basis, I feel healthier and more inspired." These comments from Mr. Lincoln's interview point to the ways that affect in classrooms was shaped by both school policies and the design decisions made by teachers and students. Sometimes care engenders care; by working to support his students in creating products that they cared about, even when constrained by the histories of the district and his own instructional practices, Mr. Lincoln found himself also feeling more engaged, more empathetic, and more cared for.

These instructional decisions, and the classrooms where they took place, illustrate how everyday experiences of care were entangled within intersecting histories. Yet, these histories were not just lived within school buildings. Classrooms are permeable; the histories and experiences of students and teachers accumulated affectively and accompanied each individual into these literacy spaces. For instance, Sara's interaction with her parents - the tension with her mom over whether to show her back to a community audience and the tears that her dad shed on reexperiencing the surgery from her 
GLIMMERS OF CARE: ATTENDING TO THE AFFECTIVE EVERYDAY

perspective-shaped how Sara experienced and designed for care. Her experience illuminates the tension inherent in schooling as students move across histories of instructional practice, school buildings, and their own lives. Histories structure affect, and thus experiences of care, through the "coagulation of intensities, surfaces, sensations, perceptions, and expressions... a thing composed of encounters and the spaces and events it traverses or inhabits" (Stewart, 2007, p. 79). Students' and teachers' experiences of care were structured by histories that were never past (Derrida, 1994). These histories and the ordinary affects that they engendered emerged within student compositions and across everyday experiences, shaping care in unexpected ways.

\section{Manipulation of Space}

During a professional development session with teachers, we collaboratively considered the ways that students interacted with classrooms and the resources within them. Whereas several of the teachers reflected that their classrooms were constrained by space, Ms. Miller, whose classroom had the smallest footprint of any of the others in this study, used this session to rethink how her students were engaging with the space. When we entered her classroom for the first time, she told us that she had requested tables rather than desks for her students, both because she felt the tables would fit better in the small space and because she thought students might engage differently with one another if they were not constrained to individual desks. Over the course of the school year, we observed Ms. Miller change the furniture in her classroom four times and the arrangement of that furniture more than 15 times, eventually removing desks from her classroom altogether (see Figure 2).

Initially, Ms. Miller's classroom featured rows of long tables facing the board. Two students shared each table, and tables were set end to end across the entire room. To visit individuals throughout the class, she had to ask students to trade places with her, which we noted disrupted the ways that students were working together. Students would stand at the front of the room or on the edges of the rows, waiting for Ms. Miller to finish her check-ins, and then they would resume their work at their seats. The only open space was a three-foot square area at the back of the classroom near an outside brick wall with a row of high windows. Each time that we observed in the first months of school, a small group of students would be huddled there on the floor. When asked about the space, Ms. Miller replied, "They needed a break, so I let them work there together." Typically, this space appeared to be occupied by the same two or three students who self-identified as Latinx. We rarely observed these students engaging in classroom activities, and they were often rendered invisible to the rest of the class because they were seated on the floor and not visible from where Ms. Miller stood at the front of the room.

Ms. Miller approached us during this class period and explained that she was excited to have the space to allow students to move. She felt that the tables had limited the ways that students could interact and that she wanted them to move whenever they felt the need. For Ms. Miller, this was a spatial and curricular redesign to extend care to her students. However, throughout the period, we observed little movement. The group of students who had been in the back corner of the room during previous observations was still located there. Whereas Ms. Miller attempted to offer students opportunities to "take space," which we took as a caring attempt to acknowledge the affect that lingered in this classroom, sticking to different bodies, her design of the learning space appeared to limit the ways that students could engage with these emotions and with one another. 


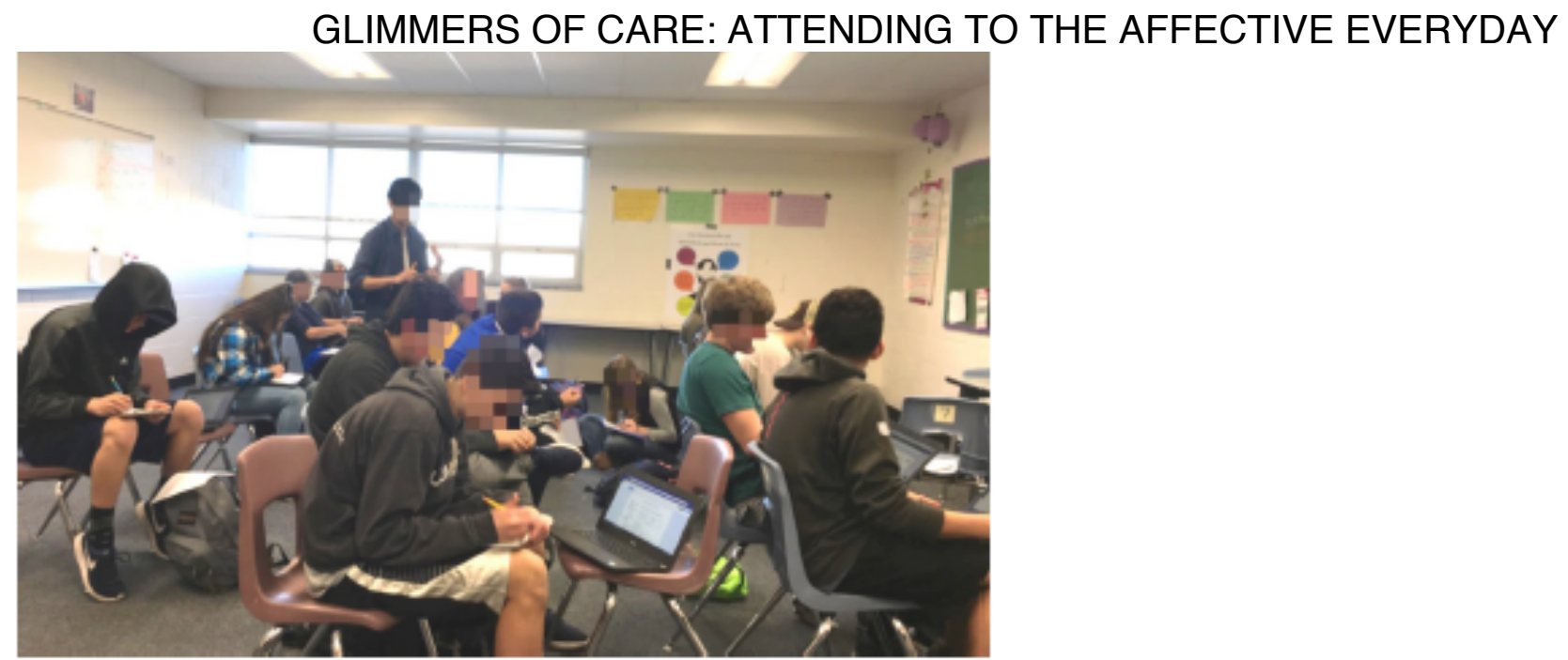

Figure 2. Ms. Miller Replaced Tables With Chairs to Give Students Space During Her Project-Based Classes

This instance of spatial manipulation glimmered for us and brightened as it was reflected in similar approaches from other teachers. Across this study, we observed numerous instances of teachers designing both space and curriculum to impact how students could engage with their instructional material and one another. Although these designs were often framed by teachers as forms of care, they were also inescapably political, interwoven with district policies, teacher and student beliefs, and power inherent within the systems and structures of education.

Throughout our data analysis, we recognized teachers' efforts to respond to how affect was structured and shifted in their classrooms. During a student's exhibit, for example, Ms. Jensen's students whose products were not "quite as ready for an audience" were placed in a back room, still part of the exhibit but separated from the works of their peers. Although this move was ostensibly to protect students who did not feel prepared, it also segregated the class products and therefore shaped how affect arose within that classroom. Similarly, in Ms. Howle's classroom, students who were "disruptive" or just "needed some space" were seated on the outskirts of the classroom. Although these moves were often the result of teachers' care for students, the manipulation of space structured how affect lingered in the classroom and stuck differently to different bodies, impacting the ways in which learning occurred in the classroom. These moves at Pine Ridge High School illuminated, as Ahmed (2015) detailed, how care can be sticky for bodies. This stickiness glimmered not only as teachers designed and manipulated space through moving objects, such as desks, that became "saturated with affect" (p. 11) but also in how that movement was entangled with shared and different histories of bodies as they moved together in these classrooms.

\section{Materialities and Modalities}

The histories of Mr. Lincoln's classroom instruction, the schoolwide culture documents, and the arrangement of Mr. Lincoln's classroom glimmered for us as we observed the ways that students took up multimodal composition, opening up certain opportunities for composition and constraining others. For example, students who took up the school's academic principles and tended to meet the requirements of the rubrics or include vocabulary words in their writing were often offered praise by Mr. Lincoln when he gave feedback on their products. This possibly shaped how students composed future products, as it alerted students that hewing closer to how the school characterized academic rigor and its school culture was rewarded with higher grades and praise from their teacher.

As Sara composed her digital story, she drew on both her personal histories - her relationship with her family and her own body - and the histories of her classroom and Mr. Lincoln's instruction. She moved from composing five vignettes about her life to pursuing a story about her surgery, and she chose this story because she could interview people who had been around her during the 
GLIMMERS OF CARE: ATTENDING TO THE AFFECTIVE EVERYDAY

surgery. She recognized that "people have very different views than I do," and wanted to explore her surgery from other people's perspectives. To do so, she planned out a storyboard, marking out where each photo would go and what words she would pair with the audio voice-over. These design decisions both glimmered with the affect surrounding Sara's experience and attended to the constraints laid out by her teacher. For Sara, the care she wanted to take with this story was bisected by care for her grade and the expectations of schooling.

Sara's care for this story was also political in that she had to make decisions about what to share (her scar and how long it would be put up on screen) and on what not to share (how her father had experienced her story through tears and how she had fought with her parents). Analysis of Sara's digital story provided glimmers into how multimodal composition is permeable and historicized, sticking to different bodies in different ways. The student products that we examined began to glimmer as we recognized that they were all entangled with students' everyday affective experiences and with the ways that schools, teachers, students, and families deemed things valuable. The care that students took with their products was often shaped by the everyday affects that they experienced in their school spaces. It is also important to note that these students were not composing their worlds in isolation from other students. Sara was negotiating her deeply felt experiences within the flows of the everyday as students around her composed stories around things such as a first school trip abroad and finding an abandoned cash register in a neighborhood tunnel.

Another example of the affective experiences of students shaping the ways that they displayed care within their products was provided by Peter, a student in Mr. Lincoln's class, who created a museum exhibit to represent his interpretation of what makes us human. Peter produced a series of sticky notes put together like an accordion and color-coded to represent the emotions that he experienced throughout the day (see Figure 3). He argued that being human was about experiencing emotions and that "without them, humans would all be bland and have no feelings whatsoever." His exhibit used multiple modes to explore how his daily world of emotions was composed as an unfolding sculpture Peter described how he hoped his audience would interact with his "Sticky Emotions" exhibit:

When you pull up the top one, all of them will follow, and you will see all of the things that represent that emotion. These represent the emotions I go through most frequently. This is an interactive exhibit. People will walk by and pull it up and see the different emotions people go through frequently. While looking at them they will think about life without them and feel how bland it would be.

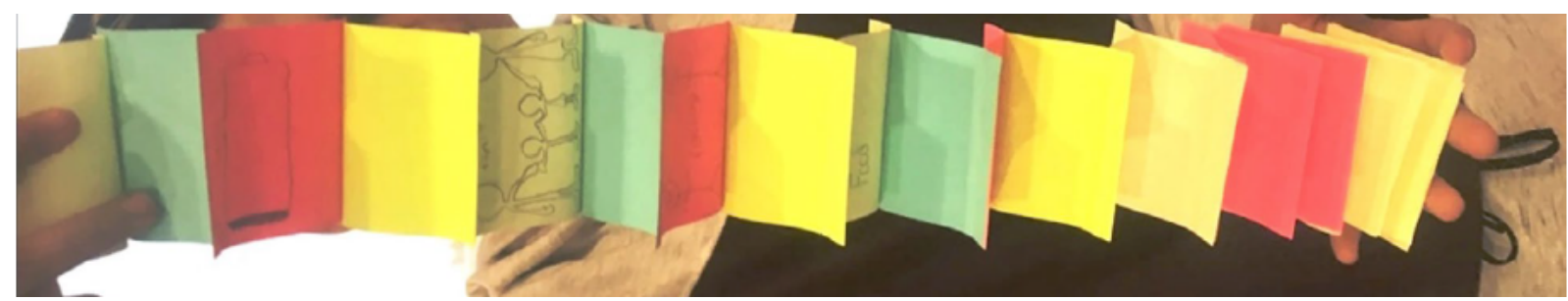

Figure 3. Peter's "Sticky Emotions Museum Artifacts Displays All the Emotions That He Might Experience In a Day

Peter designed his exhibit to represent the emotions that he felt every day in a combination of modes, asking the audience to physically pull apart his artifact to see how his emotions expanded and contracted throughout the day. Moreover, he was able to reveal not only how full of emotions each day can be but also how they expand and contract in timing and intensity through opening and closing his sticky accordion. Peter hoped that his audience, pulling his artifact's color-coded emotion sticky notes apart, would enter into a relationship with his artifact that was similar to his own. He seemed to want the assemblage around his exhibit (modality, spatiality, and bodies) to bring about a shared connection, one of caring that was entangled with his multimodal artifact and dependent on the exhibit space. As he wrote later, he did not feel that he captured "realistically" what people felt through the day despite describing himself as "calm, creative, and productive" during the project. 
GLIMMERS OF CARE: ATTENDING TO THE AFFECTIVE EVERYDAY

This illustrates how Peter might have designed to share his experiences but did not see affect captured similarly by his audience, leading him to feel a different experience of care.

What Peter's exhibit illustrates is that other bodies matter in how affect is both shaped and experienced when people engage with multimodal compositions, particularly as people folded and unfolded sticky notes that stretched out emotions throughout a day at a folding table in the school media center. Peter may have designed for people to express care through interest in his exhibit, but his audience's expression of their actual experiences did not match up with Peter's expectations of how people would experience care. This difference between expectations and reality among a group of museum attendees and a designer led affect to be structured and captured by Peter differently. Yet that experience of a minor disappointment, is also an everyday feeling in and outside of classrooms: a glimmer of disappointment that floated in that moment, possibly lingering or dissipating in the days that followed.

These multimodal products not only illuminated how classrooms were permeable spaces, influenced by how the resonance of histories and interactions that happened in school hallways and student living rooms structured affect, but also how care was not experienced as a social or individual phenomenon (Ahmed, 2015). Composition was happening with and around students as they and others drew on the everyday affects of their classroom. This everyday affect positioned and stuck to bodies, inscribing moments of care on the space. Moreover, care was experienced across bodies as both everyday (e.g., Peter designing an exhibit that brought people into his everyday experiences of emotions) and political (e.g., Sara making decisions about her surgery and how she composed around and with that experience).

\section{IMPLICATIONS}

Across our findings, multiple glimmers of everyday care coalesced. Like constellations awaiting external order, the entanglement of everyday care in histories, materials, bodies, and spaces in classrooms was uniquely felt by each student and teacher. For example, although we opened this article, as well as our findings, with a description of Sara's design decisions for her film, Torn, we could have reconfigured these same glimmers of everyday care that contributed to what Sara felt, produced, and contributed to the classroom environment; even if we did not center the design of Torn, the other glimmers of classroom life that darted before us would still collectively unfold the visions of care that built up across our analysis. Also, Ms. Bryne, in the second vignette, highlighted how the slips of care and authorship of classroom spaces were felt by Abigail (and by us as researchers experiencing this moment in person and across the field notes that we read, interpreted, and discussed). These political, everyday forms of care call for understanding how configurations of glimmers reimagine classrooms as spaces that are felt as different political environments for every student. They also require viewing the literacies of everyday care as emergent and relational, weaving across bodies in unexpected ways (Barad, 2013; Highmore, 2010). Next, we turn to how these glimmers of data must shape classroom pedagogy and how glimmers, as an analytic tool, can reimagine interpretations of affect in literacy research.

\section{Designing With Youth}

Our findings highlight the need to design care with students, instead of for students, and to view care as emergent, requiring constant redesign. Considering the contested spaces in which students must orient and move their bodies through on a daily basis, our glimmers of youth interactions reinforce the need for youth to exude more agency around the design of their learning.

With best intentions, we and the teachers codesigned this curriculum so care was both a direct and indirect focus. We were successful in many ways. The majority of students consistently self-reported on project surveys and in interviews that they felt "cared for," that their "voice was heard." Many reported that they valued working on teams in which group members helped one another and had different talents and skills to share, and our observations of classrooms echoed these students' selfreported data. Although affirming, these responses from the majority of students hid the everyday 
GLIMMERS OF CARE: ATTENDING TO THE AFFECTIVE EVERYDAY

experiences and feelings of students who did not feel care in the moment, or accumulated moments of classroom life. Sometimes there was a feeling of invisibility (e.g., "Nobody would notice if I didn't come to class") and other times a feeling of being too visible, such as an object of a teacher's unwelcome attention (e.g., "Why is she touching me?"). More subtly, sometimes projects intended to support students' identities and emerging voices as powerful communicators surfaced conflicts between artistic expression and rubrics that were connected to grades, thus exerting power and engendering compliance that was at odds with the goals of identity and artistic expression. The requirement to include music in Sara's video, for example, pushed against her own agentic vision of composition in Mr. Lincoln's class. Of particular concern was the daily reification of the meaning of schooling for students who did not feel care or felt it in painfully unintended ways, such as the unwanted touch of a teacher's hand on a student's back.

From this perspective, we might then ask educators to question where, how, and why care happens and for whom. Also, we must recognize the potential for teachers' pedagogical and caring work to cause ruptures and to be interpreted in ways that differ from how they may have intended. For the glimmers in our data when caring actions were misinterpreted and may have caused harm, we read these as generously as we could, considering how affect swiftly eddied through and around classrooms. The clusters of everyday, political care that we illustrated in the two previous vignettes required not reading actions as definitive outbursts of ethos. Rather than reading Ms. Bryne's action as coming from a sense of uncaring when she touched Abigail's back, we imagined her attempt at caring as a fleeting moment of care that attempted to exude warmth in the moment but failed in fully interpreting the wants and desires of the other actant. These were moments for considering how to redesign schooling spaces for youth agency. These moments drew out how we envisioned care in our findings as a literacy practice that was contextually bound, informing how stories were shared, compositions were designed, and spaces were interpreted.

\section{Making Care Through Multimodal Composition}

Multimodal composition was one way in which we could imagine students reshaping the ways that they were perceived by their classroom community. What if students' products and performances involved iterative development involving experimentation with modes and tools, while opening space for the final product to be more composer/designer determined? Like other project-based learning experiences, classroom instruction centered around the opportunity to compose for a real audience. Again, we saw myriad examples of these affordances of authentic literacy production reflecting student feelings in positive ways. However, there were also occurrences where class requirements were overly specified and operationalized, negatively affecting student desire.

We want students to care about what they create, while at the same time, we initiate procedures that drain the creative experience and leave the composers/makers caring less about their product and less cared for by others. In Sara's vignette presented earlier, she was intensely invested in composing her story of spinal surgery and had a clear vision for how to tell that story through graphic images that suspended on screen over multiple seconds in concert with a calm and measured first-person narration of the experience. She struggled with the teacher's requirement to include music in the soundtrack or lose rubric points. She eventually complied, but there was a residue of ill feeling that continued to resonate as she talked about how she would change the video to present only the images and disembodied voices if she could. At one level, the teacher was unaware of this student's conflict and feeling of lack of care about the way that she wanted to tell her story. Perhaps at an individual level, adjustments could have been made, but that would have negated the fact that understanding the role of music in video composition is an important learning goal, one that would be beneficial to learn. We can imagine various ways that we can transform singular assignments after the fact.More importantly, we want to center that the composing practices that students encounter in classrooms are shaped by adult expectations, by assumptions of genre and mode, and by the histories of the content that students produce or analyze. Given how histories are carried in classrooms and instructional practices and land on bodies, we also argue for the need to deeply attend to the political dimensions of care in uncovering 
GLIMMERS OF CARE: ATTENDING TO THE AFFECTIVE EVERYDAY

who has opportunities to act as a composer, designer, and artist and in what ways.

\section{Glimmers as Elucidating the Political and the Everyday}

Instead of gazing at outbursts of emotions in these data, we intentionally centered ways that care emerged in the everyday. Like Gutiérrez et al.'s (2017) recognition of ingenuity thriving constantly in historically marginalized youth, we must recognize that affect does not exist solely in big moments. Rather, glimmers allowed us to see care sluice across bodies in every class that we observed. Further, our glimpses of care reinforce that it is always tied to the political and as occurring constantly and differently for each student in our classrooms.

We argue that glimmers, looking across momentary data, allow us to question and explore the histories that shape and position historically marginalized youth in classrooms. Echoing Lewis's (2001) reflection on studying social interaction in classrooms, we know that "in any classroom, at any time, the rituals and routines are dynamic" (p. 165). Focusing on care directly - specific language, instruction, and framework-driven actions - fails to account for the human interactions that are fleeting and may otherwise "get reduced to a minor segment of an illustrative event or, perhaps, to a quick aside" (Lewis, 2001, p. 165). By using glimmers of data to interpret individual perspectives, beliefs, and needs, we imagine analytic glimmers as a tool set that can center equity for understanding everyday classroom interactions. For example, given our data set, we do not know if Peter's feelings around his sticky notes lingered or dissipated, but his experience is a call for educators and researchers to pay careful attention to the everyday moments that may seem trivial in isolation but, when glimmering in interaction with certain histories, modalities, materialities, and bodies that structure affect - those that exist both in and outside of the classroom - can be powerfully significant. These moments glimmering together can illuminate design possibilities in classrooms.

What if Ms. Bryne had noticed how Abigail's body shrank away from touch or had heard the voiced frustration with the teacher's enactment of care? Feeling empathy for Abigail, whose family had endured tragic events, Ms. Bryne heightened her expression of care for this one student. Also, although we can understand how witnesses to this moment might recoil at the teacher's actions (i.e., aren't we supposed to keep our distance?), we can also imagine how Ms. Bryne was perhaps calling up ways in which she was used to expressing care outside of school. The action was grounded in cultural, political, and historical layers of meaning. Revisiting this moment continually, we had many questions that pushed on our understanding of care and its flows across classrooms. However, as a singular glimmer into constantly changing emotions, we recognize that pedagogy is not predicated on a single touch. Rather, our glimmers of the interactions in Ms. Bryne's classroom, of Abigail's perception of Ms. Bryne as someone who "keep[s]" touching her, and of the layers of history that shaped their interactions revealed a teacher caring in ways that she knew and a student who interpreted this care in ways that it was not intended.

These glimmers do not solely illuminate researcher perspectives on classroom life, offering an assemblage of overlapping experiences, feelings, and histories. Instead, we can see how these glimmers, and the gaze through which they are collected, can elucidate new classroom designs. These are authoring opportunities, for teachers and students alike, to scribe affective guidance across the porous spaces of learning as enacted, careful literacy practices. Encouraging teachers and students to reflect on the glimmers of caring interactions within their classrooms could mark a direction in designing for a more attentive approach to care. This approach could strengthen the overall classroom community while reinforcing that individuals communicate the kinds of care that they desire themselves.

\section{CONCLUSION: GLIMMERS AND EVERYDAY SENSEMAKING}

Orellana (2016) reminded us that learning environments require seeing (and sense-making) anew:

Learning to see at B-Club involved learning to see what kids were doing, not just where they fell short of adult models of perfection. It required seeing the complexity of the tasks kids engaged in: the linguistic, cultural, cognitive, and social demands, all bound up together, and the strategies participants used to adapt to these 


\section{challenges. (p. 120)}

GLIMMERS OF CARE: ATTENDING TO THE AFFECTIVE EVERYDAY

The kinds of assignments and work that students are asked to perform on a daily basis, and the small and big social interactions of instruction, learning, and play, all unfold within the political that can constitute, yet also obscure, how the everyday unfolds in and out of schools. Particularly in the English classrooms within this study, we saw how the role of literature and class-assigned texts was "bound up" with the complex lives and interests of the students being taught. Similarly, we saw how forms of standards-aligned writing tasks could engage students in developing and expressing their expanding selves. In this study, students were engaged in project-based learning in collaborative social contexts where they individually and collectively composed and produced products and performances using a range of physical and digital materials and tools. Our analysis of students' experiences in designing museum exhibits and digital stories for authentic audiences suggests that multimodal composition can open up spaces for care. We observed how some students flourished as learners when they had instructional support and creative freedom to communicate through visual, sound, moving, and tactile modes, in addition to writing. The use of digital tools facilitated the crossing of school and home lives and fed into students' identities as skillful producers and designers. These new multimodal environments elicited demonstrations of care for self and others as students worked and played together. Further, these environments suggest the power of multimodality as to engender affective space. We conjecture that the act of multimodal composing is an artistic experience that allows one to be vulnerable through multimodal ensembles that go beyond words and, in that vulnerability, to know and care for one another more deeply. Of course, for this to happen, students need to be composing about things that matter to them, for real purposes and real audiences. That is a strength of project-based learning but can also happen in other inquiry learning and ELA contexts.

Across the classrooms in our study, there was a tension among layers of individual and collective histories, the design of classrooms, and how school policies were lived in classrooms. These tensions informed how, where, and who enacted care and in what ways that enactment was felt across and within bodies. Care, as a literacy practice in and of itself, was informed by and entangled with the many ways that literacies emerged in these classrooms, including but not limited to the multimodal products that students composed. Although we call for further affective explorations of the practice of caring in teacher instruction, and in how spatial and temporal factors shape contexts of political care, we are also mindful of these questions as "bound up" in a present moment. Our research of everyday political care, too, recognizes the detritus of sociocultural complexity that Orellana (2016) described and also considers the need to attend to visceral and emergent sensations glimmering in classrooms. Pragmatically, we continue to work with the teachers of the Compose Our World project, seeking to support and care alongside the communities with which we have been working and feeling.

Like Orellana's(2016)view of vibrant activity at B-Club, our glimmers of everyday care in the classrooms in this study highlighted the complexity of activities, histories, and feelings that gleamed across our data daily. Stare at the brightness of a match's dancing flame or the glimmers of fireflies in the dark long enough, and their ephemerality endures even after the light has extinguished. So, too, our gaze at the every, political care lingers on us as teacher educators and researchers.

Left sensing care that is otherwise invisible in the daily and political interactions in classrooms, like flickering glimmers pressed on the insides of our eyelids, we consider this methodological resonance one that opens up possibilities for pedagogy, classroom support, and reimaging new classroom possibilities. Looking across the glimmers that composed our data, we see joy twinkling consistently across the classrooms in this study. They are the fireflies that shine and dim, sporadically as reminders of the caring that undergirds and moves alongside histories, policies, and pedagogies of classrooms. We hold fast to the glimmers of care that speak to the everyday possibilities of brighter, warmer classrooms and literacy practices. 


\section{GLIMMERS OF CARE: ATTENDING TO THE AFFECTIVE EVERYDAY}

\section{NOTES}

Funding for this research was provided by the George Lucas Educational Foundation. We thank the Compose Our World design team for their contribution to this work, including Alison Boardman, Joseph Polman, Bud Hunt, Karla Scornavacco, and Ashley Potvin. We also thank the myriad teachers, doctoral students, and high school students who allowed us to explore the themes of care and affect alongside them.

\section{REFERENCES}

Ahmed, S. (2000). Strange encounters: Embodied others in postcoloniality. New York, NY: Routledge.

Ahmed, S. (2015). The cultural politics of emotion (2nd ed.). New York, NY: Routledge.

Barad, K. (2010). Quantum entanglements and hauntological relations of inheritance: Dis/continuities, spacetime enfoldings, and justice to-come. Derrida Today, 3(2), 240-268. https://doi.org/10.3366/drt.2010.0206

Barad, K. (2013). Ma(r)king time: Material entanglements and rememberings: Cutting together-apart. In P.R. Carlile, D. Nicolini, A. Langley, \& H. Tsoukas (Eds.), How matter matters: Objects, artifacts, and materiality in organization studies (pp. 16-31). Oxford, UK: Oxford University Press.

Boardman, A., Garcia, A., \& Dalton, B. (in press). Compose our world: Engaging educators and students with projectbased learning in secondary English language arts. New York, NY: Teachers College Press.

Collaborative for Academic, Social, and Emotional Learning. (n.d.).What is SEL? Chicago, IL: Author. Retrieved from https://casel.org/ what-is-sel/

Dalton, B., Robinson, K., Lovvorn, J.F., Smith, B.E., Alvey, T., Mo, E., ... Proctor, C.P. (2015). Fifth grade students' digital retellings and the Common Core: Modal use and design intentionality. The Elementary School Journal, 115(4), 548-569. https://doi.org/10.1086/681969

Derrida, J. (1994). Specters of Marx: The state of the debt, the work of mourning and the new international (P. Kamuf, Trans.). New York, NY: Routledge.

Dutro, E. (2013). Toward a pedagogy of the incomprehensible: Trauma and the imperative of critical witness in literacy classroom. Pedagogies, 8(4), 301-315. https://doi.org/10.1080/1554480X.2013.829280

Dutro,E. (2019).Visceral literacies, political intensities: Affect as critical potential in literacy research and practice. In K.M. Leander \& C. Ehret (Eds.), Affect in literacy learning and teaching: Pedagogies, politics and coming to know (pp. 73-91). New York, NY: Routledge.

Ehret, C., \& Hollett, T. (2014). Embodied composition in real virtualities: Adolescents' literacy practices and felt experiences moving with digital, mobile devices in school. Research in the Teaching of English, 48(4), 428-436.

Ehret, C., \& Leander, K.M. (2019). Introduction. In K.M. Leander \& C. Ehret (Eds.), Affect in literacy learning and teaching: Pedagogies, politics and coming to know (pp. 1-19). New York, NY: Routledge.

Elias, M.J., Zins, J.E., Weissberg, R.P., Frey, K.S., Greenberg, M.T., Haynes, N.M., ... Shriver, T.P. (1997).

Promoting social and emotional learning: Guidelines for educators. Alexandria, VA: Association for Supervision and Curriculum Development.

Fosha, D., Siegel, D.J., \& Solomon, M.F. (Eds.). (2009). The healing power of emotion: Affective neuroscience, development and clinical practice. New York, NY: W.W. Norton.

Freire, P. (2000). Pedagogy of the oppressed (30th anniv. ed.; M.B. Ramos, Trans.). New York, NY: Continuum.

Gutiérrez, K.D. (2008). Developing a sociocritical literacy in the third space. Reading Research Quarterly, 43(2), 148164. https://doi.org/ 10.1598/RRQ.43.2.3

Gutiérrez, K.D., Cortes, K., Cortez, A., DiGiacomo, D., Higgs, J., Johnson, P., .. Vakil, S. (2017). Replacing representation with imagination: Finding ingenuity in everyday practices. Review of Research in Education, 41(1), 30-60. https://doi.org/10.3102/0091732X16687523

Highmore, B.(2010). Bitter after taste: Affect, food, and social aesthetics. In M. Gregg \& G.J. Seigworth (Eds.), The affect theory reader (pp. 118-137). Durham, NC: Duke University Press.

Hinchliffe, S. (2000). Entangled humans: Specifying powers and their spatialities. In J.P. Sharp, P. Routledge, C. Philo, \& R. Paddison (Eds.), Entanglements of power: Geographies of domination/resistance (pp. 219-237).London, UK: Routledge.

Hoffman, D.M. (2009). Reflecting on social emotional learning: A critical perspective on trends in the United States. Review of Educational Research, 79(2), 533-556.https://doi.org/10.3102/0034654308325184

Kirshner, B. (2015). Youth activism in an era of education inequality. New York, NY: New York University Press.

Kraftl,P., \& Adey,P.(2008). Architecture/affect/inhabitation: Geographies of being-in buildings. Annals of the Association of American Geographers, 98(1), 213-231. https://doi.org/10.1080/00045600701734687 


\section{GLIMMERS OF CARE: ATTENDING TO THE AFFECTIVE EVERYDAY}

Kress, G. (2003). Literacy in the new media age. New York, NY: Routledge.

Kuby, C.R., Gutshall Rucker, T., \& Kirchhofer, J.M. (2015). 'Go be a writer': Intra-activity with materials, time and space in literacy learning. Journal of Early Childhood Literacy, 15(3), 394-419 https://doi.org/10.1177/1468798414566702

Leander, K., \& Boldt, G. (2013). Rereading "A pedagogy of multiliteracies": Bodies, texts, and emergence. Journal of Literacy Research, 45(1), 22-46. https://doi.org/10.1177/1086296X12468587

Lenters, K. (2016). Riding the lines and overwriting in the margins: Affect and multimodal literacy practices. Journal of Literacy Research, 48(3), 280-316.https://doi.org/10.1177/1086296X16658982

Lenters, K. (2019). Charlene's puppies: Embarrassing obsessions or vibrant matter entangled in ethical literacies? In K.M. Leander \& C. Ehret (Eds.), Affect in literacy learning and teaching: Pedagogies, politics and coming to know (pp. 50-66). New York, NY: Routledge.

Lewis, C. (2001). Literary practices as social acts: Power, status, and cultural norms in the classroom. Mahwah, NJ: Erlbaum.

Lewis, C., \& Tierney, J.D. (2011). Mobilizing emotion in an urban English classroom. Changing English, 18(3), 319329. https://doi. org/10.1080/1358684X.2011.602840

Massumi, B. (2002). Parables for the virtual: Movement, affect, sensation. Durham, NC: Duke University Press.

Massumi, B. (2015). Politics of affect. Hoboken, NJ: John Wiley \& Sons.

Meyer, A., Rose, D.H., \& Gordon, D. (2014). Universal design for learning: Theory and practice. Wakefield, MA: CAST Professional.

Muñoz,J.E. (1996). Ephemera as evidence: Introductory notes to queer acts. Women \& Performance, 8(2), 16. https://doi.org/10.1080/07407709608571228

New London Group. (1996). A pedagogy of multiliteracies: Designing social futures. Harvard Educational Review, 66(1), 60-93. https:// doi.org/10.17763/haer.66.1.17370n67v22j160u

Noddings, N. (1992). The challenge to care in schools. New York, NY: Teachers College Press.

Noddings, N. (2006). Educating whole people: A response to Jonathan Cohen. Harvard Educational Review, 76(2), 238-242. https://doi. org/10.17763/haer.76.2.7538k44848065xw2

Orellana, M.F. (2016). Immigrant children in transcultural spaces: Language, learning, and love. New York, NY: Routledge.

Osher, D., Kidron, Y., Brackett, M., Dymnicki, A., Jones, S., \& Weissberg, R.P. (2016). Advancing the science and practice of social and emotional learning: Looking back and moving forward. Review of Research in Education, 40(1), 644-681. https://doi.org/10.3102/0091732X16673595

Polman, J.L. (2012). Trajectories of participation and identification in learning communities involving disciplinary practices. In D.Y.Dai (Ed.), Design research on learning and thinking in educational settings: Enhancing intellectual growth and functioning (pp. 225-242).New York, NY: Routledge.

Polman, J.L., Stamatis, K., Boardman, A., \& Garcia, A. (2018). Authentic to whom and what? The role of authenticity in project-based learning in English language arts. In J.Kay \& R. Luckin (Eds.), Rethinking learning in the digital age: Making the learning sciences count: 13th International Conference of the Learning Sciences (ICLS) 2018 (Vol. 2, pp. 1669-1670). London, UK: International Society of the Learning Sciences.

Spinoza, B. (2000). Ethics (G.H.R. Parkinson, Ed. \& Trans.). New York, NY: Oxford University Press.

Stewart, K. (2007). Ordinary affects. Durham, NC: Duke University Press. Stewart, K. (2014). Road registers. Cultural Geographies,21(4),549-563. https://doi.org/10.1177/1474474014525053

Vadeboncoeur, J.A., \& Collie, R.J. (2013). Locating social and emotional learning in school environments: A Vygotskian perspective on learning as unified. Mind, Culture, and Activity, 20(3), 201-225. https://doi.org/10.1080/10749039.2012.755205

Valenzuela, A. (1999). Subtractive schooling: U.S.-Mexican youth and the politics of caring. Albany: State University of New York Press.

Vasudevan, L.M. (2014). Multimodal cosmopolitanism: Cultivating belonging in everyday moments with youth. Curriculum Inquiry, 44(1), 45-67. https://doi.org/10.1111/curi.12040

Vasudevan,L., Schultz,K., \& Bateman, J. (2010). Rethinking composing in a digital age: Authoring literate identities through multimodal storytelling. Written Communication, 27(4), 442-468. https://doi.org/10.1177/0741088310378217

Williamson, A.A., Modecki, K.L., \& Guerra, N.G. (2015). SEL programs in high school. In J.A. Durlak, C.E. Domitrovich, R.P. Weissberg, \& T.P. Gullotta (Eds.), Handbook of social and emotional learning: Research and practice (pp. 181 196). New York, NY: Guilford.

Zembylas, M. (2016). Making sense of the complex entanglement between emotion and pedagogy: Contributions of the affective turn. Cultural Studies of Science Education, 11(3), 539-550. https://doi. org/10.1007/s11422-014-9623-y

Submitted April 1,2019

Final revision received November 8,2019

Accepted November 18,2019 